\title{
Performance of non-Newtonian fluid in vertical annuli with and without rotation of inner cylinder
}

\author{
Lina Jassim ${ }^{1, *}$, Basima S. Khalaf ${ }^{2}$, Abeer Hashim ${ }^{3}$

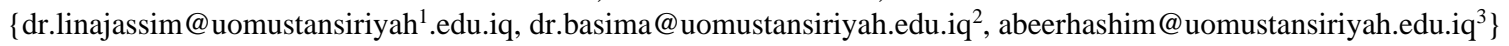 \\ Mechanical Department- Engineering college-Mustansiriyah University -Iraq 1,2,3
}

\begin{abstract}
A simulation model of non-Newtonian fluid in vertical, concentric annular flow is used in this work. A prototype of a drilling device is manufactured to compare with the simulation results. Water-based mud rheology is described here with the Bingham plastic model. The simulation results reveal that Bingham plastic fluid has a good attitude during drill pipe rotation in terms of axial velocity, tangential velocity, and molecular viscosity. This influence of rotation on the axial velocity is mirrored in the behavior of the shear stresses inside annular space and hence on the friction factor. However, the rest situation of the drill pipe results in high fluid viscosity. Furthermore, it is found that 0.2 of eccentricity leads to increase the pressure drop inside annuli. Bingham plastic fluid has a great dependence on temperature, and the temperature decreases from top to bottom. This behavior occurs since Bingham fluid flows from up to down during drilling.
\end{abstract}

Keywords: RANs; Annular flow; Inner wall rotation; Wall shear stress; Axial velocity; drilling.

\section{Introduction}

In drilling operation of oil and gas wellbores, non-Newtonian fluid is pumped through the drill string out from drill bit nozzles through annular space between the drill string and casing walls. At the surface, non-Newtonian fluid is separated from the rocks and recirculated. This fluid has certain functions; the most effective duties are cleaning the well and managing the wellbore pressure while drilling operation. To drill at a certain depth, the non-Newtonian fluid must supply the required hydrostatic pressure to prevent formation damage and maintain the wellbore stability.

Active interest in the wellbore drilling circumstances has been studied in a large number of works. These circumstances include the drill pipe situations of vertical, horizontal as well as directional position. Moreover, drilling fluid composition plays a vital role in carrying the rock cuttings and clean the hole. Numerous studies have attempted to explain carrying cuttings in horizontal and deviated wellbores experimentally [1,2] and numerically [3-6]. The topic of drilling fluid composition is one of the most crucial areas in drilling technology research today. Werner and his group [7] mentioned the significant relationship between viscoelastic properties of oil-based and water-based drilling fluids with hole cleaning ability. In another study, Gulraiz and Gray, (2020) [8] performed a numerical analysis of plug viscosity effect on pressure drop profile and carrying cuttings. Adding nanoparticles to the drilling fluid has been used to enhance fluids' ability to clean the hole efficiently [9], and [10].

Drilling fluid is non-Newtonian fluid, which can be aqueous-based fluid or non-aqueous based fluid depending on the continuous phase while the rest are chemical additives. Escudier and research team [11] did an experimental and numerical study of aqueous fluids inside concentric and $80 \%$ eccentric annular space with and without inner cylinder rotation. Aqueous based fluids can behave as a Herschel-Bulkley model or Bingham plastic model depending on its consistency. In 2005, Ahmed reported the polymer-based fluid behaved as Hershel-Bulkley model inside concentric and eccentric annular space with center body rotation, and Skjold [12] agreed with Ahmed that pressure drop augmented with rotational speed according to the shear thinning phenomenon.

The knowledge of pressure drop inside annuli is significant to drill and circulate fluid efficiently. As a result, a considerable amount of literature has been focused on pressure drop as well as temperature distribution during not only drilling operation but also casing and production operation through annular space. Pressure losses were investigated by Kelessidis et al., [13] and Okon and Udoh [14]. Wang and his team [15] did the most relevant study, their study concentrated on the wellbore temperature and pressure distribution during supercritical $\mathrm{CO} 2$ fracturing flow back process. They found that wellbore pressure and temperature were gradually decreasing from the bottom to the top during the $\mathrm{CO} 2$ flow back process. The wellbore temperature is the most effective factor that has precise control of managing wellbore pressure during the controlled gradient drilling. Yang [16] predicted the wellbore 
temperature using a hollow balls technique. The balls were injected with drilling fluid inside drill string, then separated inside annulus using a cyclone separator. The wellbore temperature prediction was done using a numerical simulation.

The investigation of temperature distribution in the directional drilling process has become widely popular. Drilling and production of horizontal wells are complex; therefore, the distributed temperature sensor technique was used to provide the downhole temperature data accurately [17]. Mahdiani and Khamehchi [18] used a new model to research the temperature profile in a gas lift well. This model introduces the faster way to calculate the wellbore temperature profile by the combination of the heat transfer balance method with the linear method. As mentioned, most of the previous studies focused on either carrying cuttings or pressure drop analysis in different annular geometries. Few references in the literature systematically describe in detail the completely static and dynamic drilling operation conditions. In this work, we combined the most effective factors mentioned in a vertical drilling operation using CFD Ansys Fluent package. The effect of varying of drill pipe rotational speeds on the pressure drop, shear wall stress as well as skin friction coefficient in the borehole was investigated numerically. Furthermore, the variation of temperature distribution and molecular viscosity along the pipe length was also conducted numerically. In addition, an experimental flow loop simulator was manufactured to analyze and compare with the simulation results in terms of pressure drop while drilling operation. The carrying amount of breaking gravels was also investigated experimentally.

\section{Project Methodology}

\subsection{Simulation model of non-Newtonian fluid inside annuli}

Bingham fluid model gathered with Navier-Stokes equations are used to simulate incompressible, laminar flow, fully developed of water-based mud inside concentric annuli with and without rotation. The numerical approach of [11] is proposed here to study the bulk axial flow inside annuli with the rotation of the drill pipe. Therefore, the governing equations are:

Bingham plastic model is expressed as:

$$
\tau=\tau_{y}+\mu_{p} \cdot \gamma
$$

Where, $\tau$ is shear stress, Pa., $\tau_{y}$ is yield stress, which was $2 \mathrm{~Pa}$. from the experiment, $\mu_{p}$ is the plastic viscosity Pa.s, which was 32 Pa.s and $\dot{\gamma}$ is the shear rate in rad/s. (10, 17, 170,340, 510, $\left.1021 \mathrm{~s}^{-1}\right)$. Continuity and momentum equations for non-Newtonian fluid inside concentric annuli with the rotation of the inner cylinder (drill pipe) are in cylindrical coordinates.

$$
\begin{aligned}
& \frac{\partial \bar{w}}{\partial \bar{r}}+\frac{\bar{w}}{-}+\frac{1}{r} \frac{\partial \bar{v}}{\partial \phi}+\frac{\partial \bar{u}}{\partial z}=0
\end{aligned}
$$

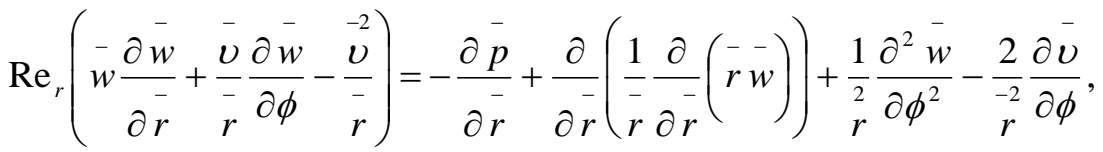

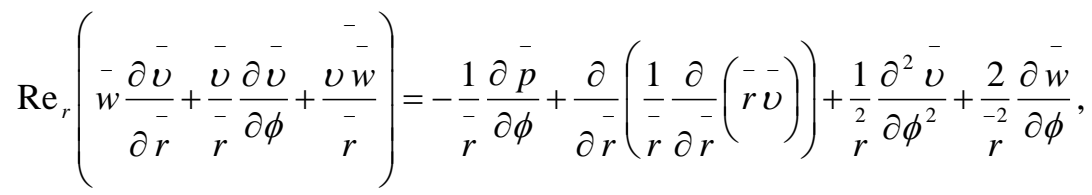

$$
\begin{aligned}
& \operatorname{Re}_{r}\left(-\frac{\partial \bar{u}}{\partial \bar{r}}+\frac{\bar{v}}{\bar{r}} \frac{\partial \bar{u}}{\partial \phi}\right)=\frac{1}{2} f . \operatorname{Re}+\frac{1}{r} \frac{\partial}{\partial \bar{r}}\left(\bar{r} \frac{\partial}{\partial \bar{r}}\left(\bar{r} \frac{-\bar{u}}{\partial \bar{r}}\right)\right)+\frac{1}{2} \frac{\partial^{2} \bar{u}}{\partial \phi^{2}} \\
& \frac{\partial}{\partial r}(\bar{r} w)+\frac{\partial \bar{v}}{\partial \phi}=0
\end{aligned}
$$


The boundary conditions that are applied to solve these equations are: In annular space, there are two cylinders, one presents the formation wall, therefore; $\omega=u=v=0$, and the other is drill pipe see Fig.1. (geometry of control volume), thus; $\bar{\omega}=\bar{u}=0$, while the rotation of the drill pipe is represented by tangential velocity $\bar{v}=1$.

In this study, heat transfer and pressure drop are considered with depth only. Since the temperature and pressure of mud inside annuli gradually decrease with the decreasing depth and geothermal gradient, [19] heat transfer model is used, however, this study considers heat conduction rather than heat convection and heat generation. Therefore, the rate of energy by conduction can be calculated as in equation. 7 and insert the Bingham model as the user defines the function in computational fluid dynamic (Fluent package).

$$
\frac{1}{r} \frac{\partial}{\partial \vec{r}}\left(\overline{r k} \frac{\partial T}{\partial \bar{r}}\right)=\frac{1}{r^{2}} \frac{\partial T}{\partial \phi}\left(\frac{k \partial T}{\partial \phi}\right)+\frac{\partial}{\partial z}\left(\frac{k \partial T}{\partial z}\right),
$$

For the vertical wells, there is an overall temperature rise of $242^{\circ} \mathrm{K}$ from the outlet to inlet. The primary fluid used for the analysis was non-Newtonian Bingham fluid. The solver used was the commercial CFD Fluent package. The solution was done in RANs mode. In order to ensure the accuracy of our solution, the convergence of the solution has to check, and it was achieved at 10 e-5 residuals after 235 iterations. The residual reveals the differences between the guessing and the calculated magnitude of the outputs (Velocity profiles fluid, energy, and continuity). Furthermore, Grid Independence Test (GIT) was studied to confirm that the output parameter (pressure drop) was static in conjunction with the number of grids, demonstrated in Fig. 2. This test was conducted with a different number of cells (different types of grid), which were coarse type (14260 cells), medium type of grid ( 24212 cells), a fine type of grid (31234 cells), and extra-fine type of grid (39876 cells). As a result, 31234 cells were selected according to the high similarity with 39876 cells and to optimize the time of iterations.

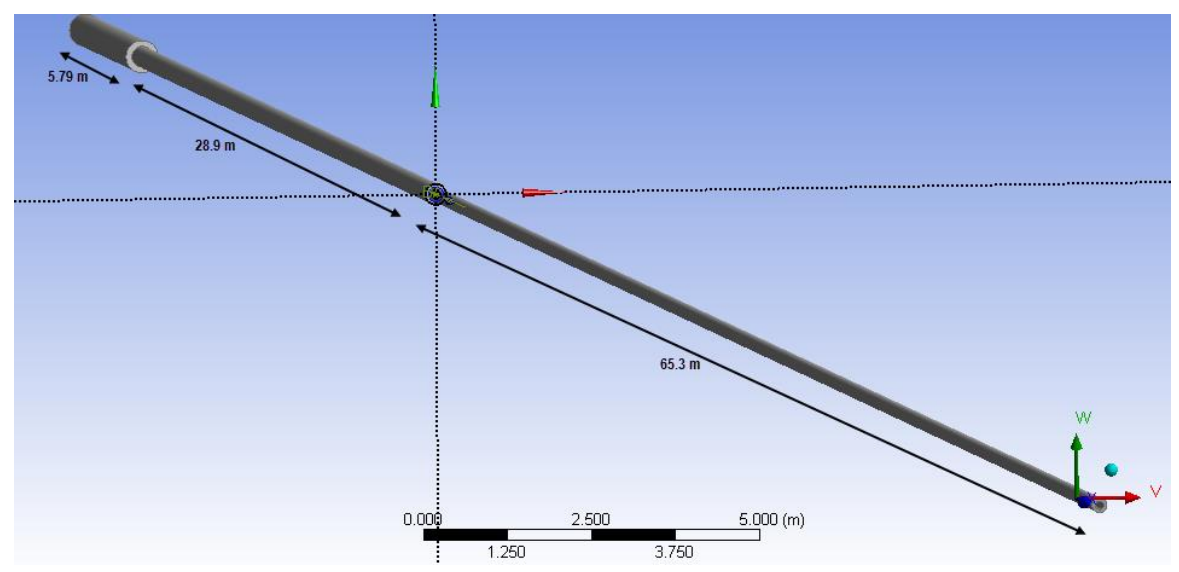

Fig. 1. The control volume of this work, the dimensions simulates real drill string

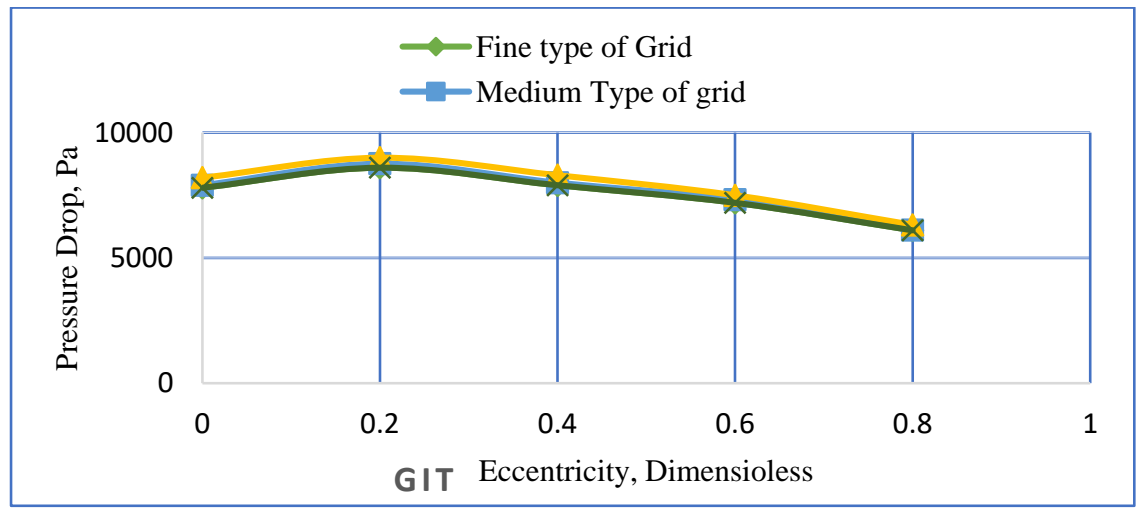

Fig. 2. Grid independency test for pressure drop inside annuli 


\subsection{Experimental rig}

The experimental device was designed to predict the pressure drop inside annuli, as well as to investigate the drilling fluid ability to carry the cuttings. Figure 3 illustrates the drilling rig components. In present work, the test section consists of eleven parts as explained below:

1. Derrick

2. Swivel

3. Annular space

4. Drill pipe

5. Gear box

6. Drill bit

7. Centrifugal pump

8. Flow meter

9. Manometer

10. Water based fluid

11. Drilled cuttings separator

The dimensions of the test section are $2.3 \mathrm{~cm}$ of drill pipe diameter with a length of $60 \mathrm{~cm}$. While the formation was simulated by a PVC plastic pipe of $5.3 \mathrm{~cm}$ diameter and length of $1 \mathrm{~m}$. For the cuttings are gravels with a weight of $1600 \mathrm{gm}$. and $1403 \mathrm{~kg} / \mathrm{m} 3$ of density. Water-based mud was the carrier fluid inside the circulation system. Drilling fluid was formulated according to API standard at the University of Technology, Petroleum department lab using 22.5 gm. of Bentonite and $350 \mathrm{ml}$ of water under $1200 \mathrm{rpm}$ of high shear rate of mixing for 30 minutes. Rheology of the carrier fluid was plastic viscosity of 30 Pa.s and yield stress was 12 Pa.s. The density of fluid was $833 \mathrm{~kg} / \mathrm{m} 3$ and the prepared amount was three liters. Two types of movement, which are rotational and longitudinal movements. The rotational movement represents by the gearbox while the longitudinal movement represents by bully moved manually via the drill line. The drill pipe rotational speed was $100 \mathrm{rpm}$ and $0 \mathrm{rpm}$. Accordingly, this formulated fluid was supplied the sufficient hydrostatic pressure as the following:

$$
\text { Hydrostatic pressure }(\mathrm{psi})=0.052 . \rho . T V D
$$

Where $\rho$ is the water-based fluid density, which was measured at the lab and equals to $8.33 \mathrm{ppg}$. TVD is the true vertical depth (ft) and is the hole depth equaled to $3.28 \mathrm{ft}$. To start the experiment, firstly; the calibration of rig test was done using Newtonian fluid (water) as the circulated fluid and plastic cuttings of $341 \mathrm{~kg} / \mathrm{m} 3$ density. After that, water-based drilling fluid was used as a carrier fluid and gravels as the formation.

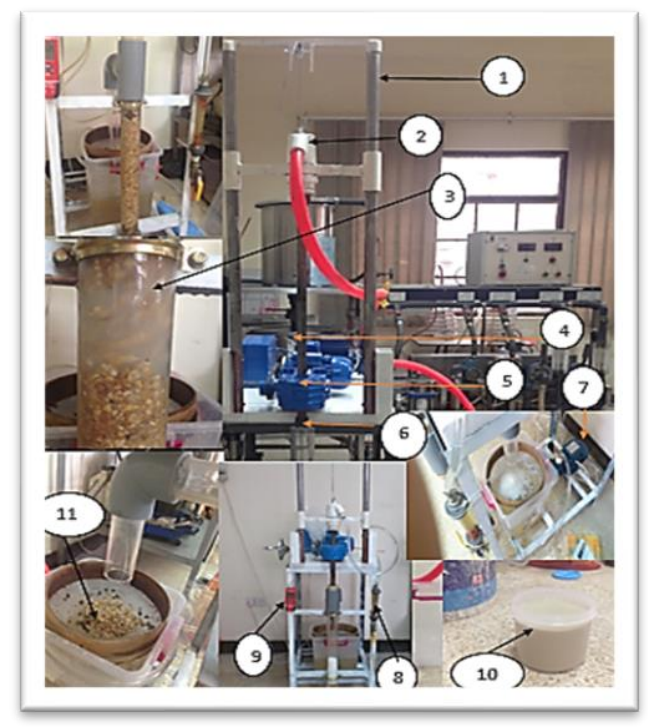

Fig. 3. A prototype of drilling rig 


\section{Results and Discussion}

\subsection{CFD simulation results}

\subsubsection{The effect of inner cylinder rotation}

The effect of inner cylinder rotation in vertical wells is analyzed in this section. Figure 4 shows the performance of non-Newtonian fluid during pausing and running of the drill pipe. As expected, the non-Newtonian fluid accumulates towards one side of the well as shown in contour 1, however; it is homogenized at $100 \mathrm{rpm}$ of inner cylinder speed rotation (contour 2). Since both inner and outer walls velocity is zero at (contour 1). This can be interpreted in nonNewtonian fluid viscosity (contour 3), which is obviously high comparing to the state of rotation (contour 4). This behavior is according to the high shear stress that affects non-Newtonian viscosity. The axial velocity of fluid inside annuli is shown in Fig. 4 contours (5 and 6 ) for pausing and running of rotation. This attitude occurs because of well mixing during $100 \mathrm{rpm}$ of drill pipe or while rotation of the inner cylinder.

The major cause of the pressure drop is energy loss created by the high viscosity of the fluid, as well as head loss according to friction between the drill pipe and the rocks. Since pressure drop investigation is significant to manage wellbore pressure, therefore; the effect of eccentricities was also studied in this work to compare and validate with the published study of Tang and his research group [20] as shown in Fig. 5. The average error between Tang et al, 2019, and our results of pressure drop along pipe length is $7.2 \%$, and this percentage can be considered as an acceptable range. This numerical result found that peak pressure drop is at an eccentricity of 0.2. It was also found that, after this point, with an increase in eccentricity pressure drop decreases. The reason is the fluid can escape through the additional area created by the eccentricity. This will result in a low-pressure drop.
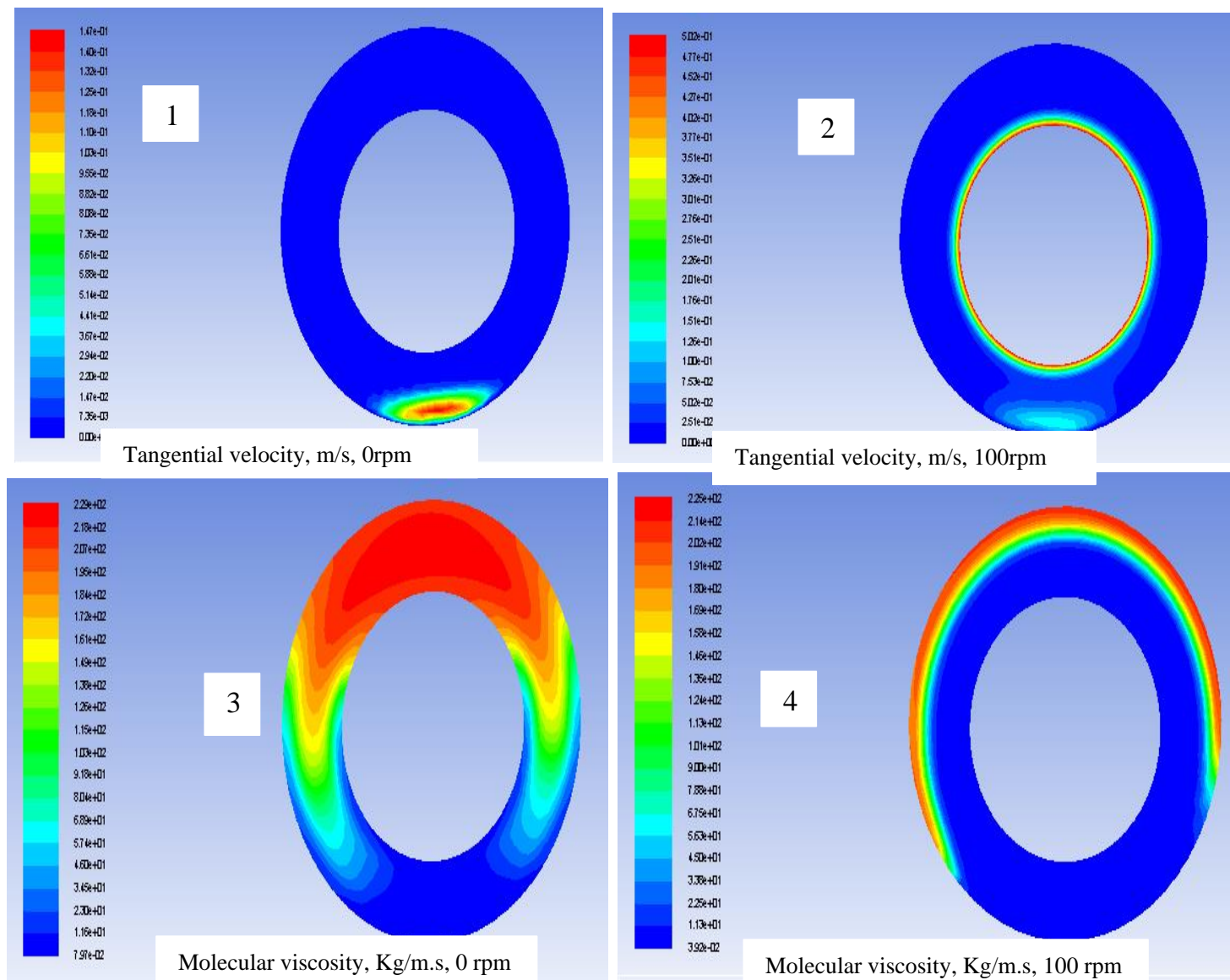


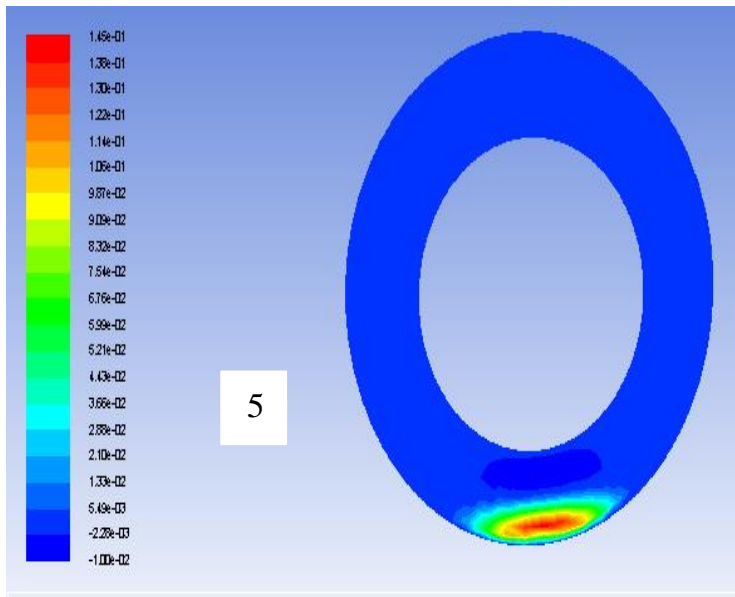

Axial velocity $\mathrm{m} / \mathrm{s}, 0 \mathrm{rpm}$

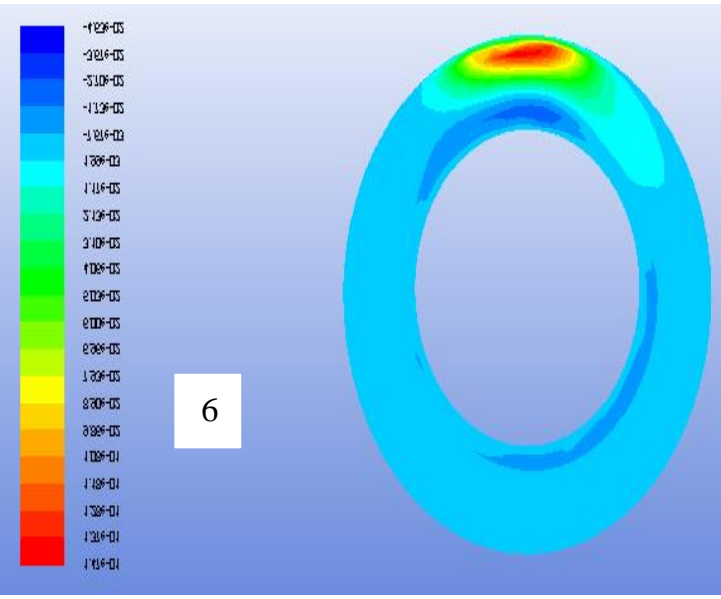

Axial velocity m/s, 100rpm

Fig. 4. The annular velocity of fluid and mixture with and without rotation

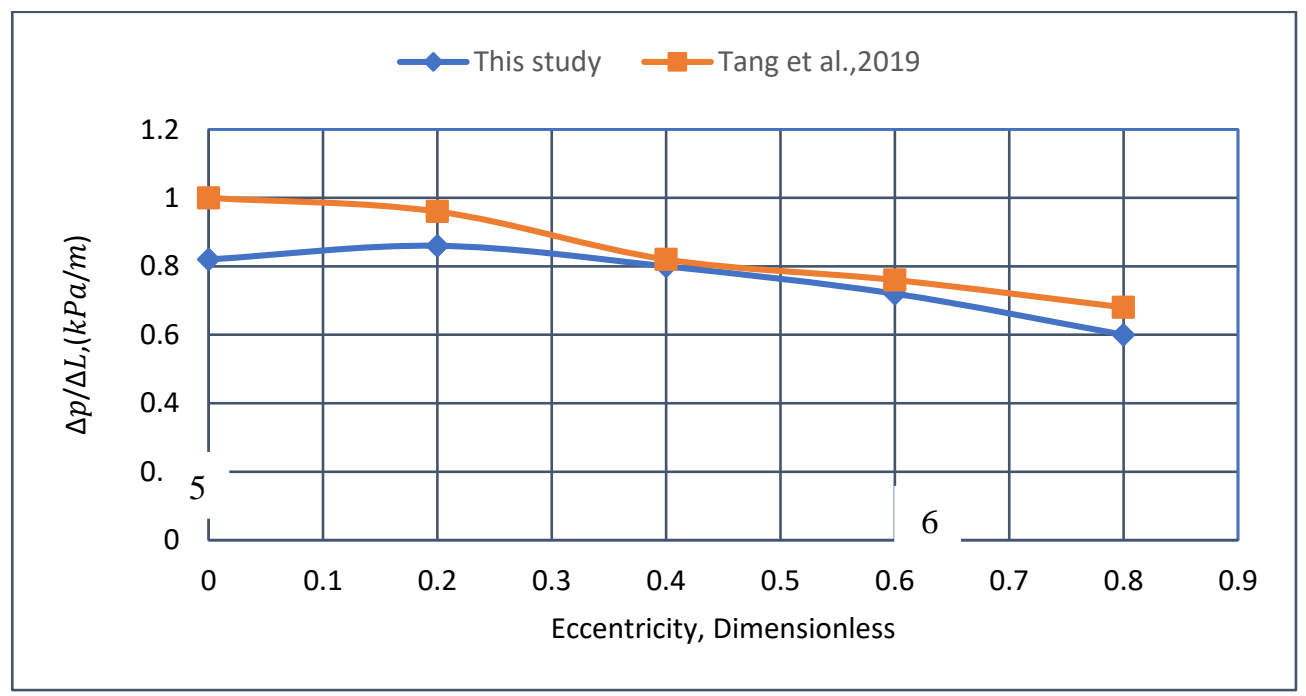

Fig. 5. Comparing between this work and Tang 2019 in terms of pressure drop with eccentricity

The associated temperature variation happening due to the depth of the well is plotted in Fig. 6 . It is clear that towards depth, temperature decreases from 544 to $303^{\circ} \mathrm{K}$. This behavior occurred since Bingham fluid flows from up to down. As a result, drill pipe cooling was done. 


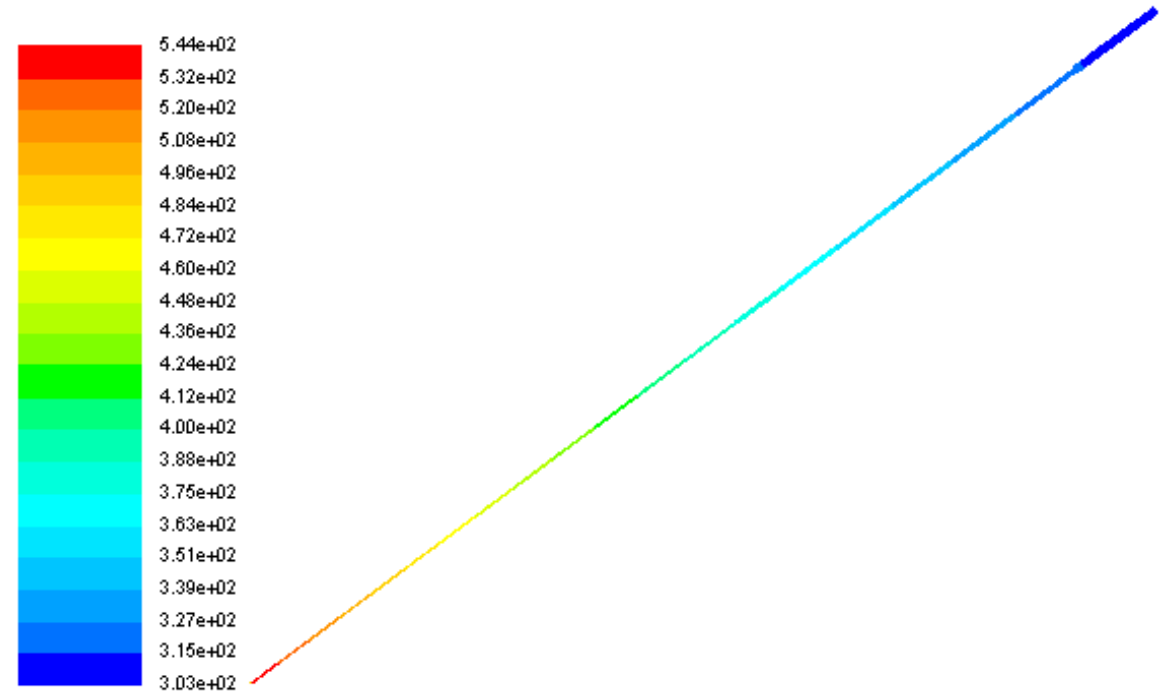

Fig. 6. Temperature $(\mathrm{K})$ variation along the pipe length

The variation of molecular viscosity with temperature is plotted in Fig. 7. It is evident that the Bingham plastic fluid has a great dependence on temperature. The temperature has an opposite effect on the viscosity. Viscosity has a variation of 1.7 to $8.24 \mathrm{~kg} / \mathrm{m} . \mathrm{s}$ for the temperature variation shown in Fig. 6.

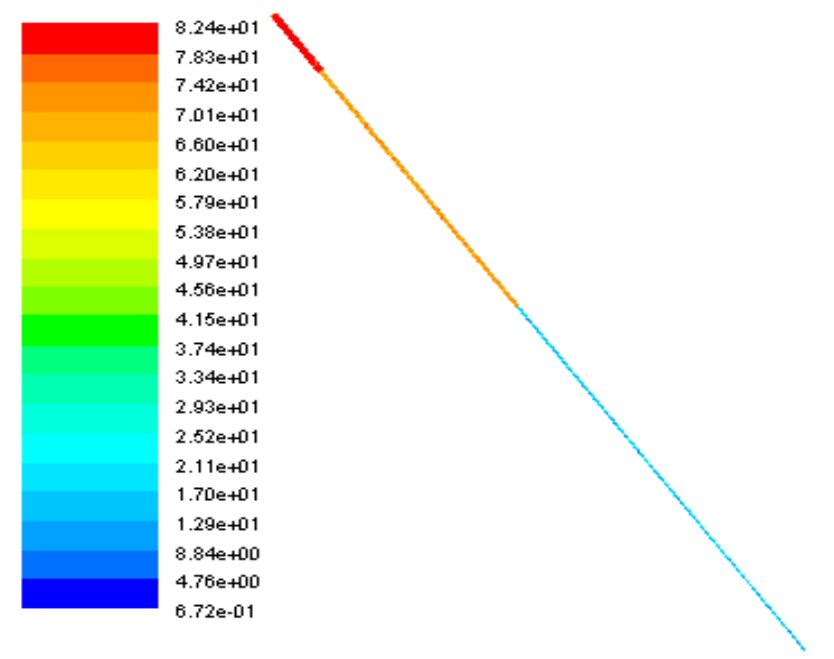

Fig. 7. Variation of molecular viscosity $(\mathrm{Kg} / \mathrm{m} . \mathrm{s})$ with temperature

The analysis was done for different inner rotational speeds. Apart from the molecular viscosity, the results found to have a significant variation with the rotational speed. Since the temperature variation is the same for different rotational speeds, molecular viscosity remains the same. Variation in pressure drop as a function of rotational speed is shown in Fig.8, here both the pressure drop and speed are plotted in logarithmic scale for better visibility. 


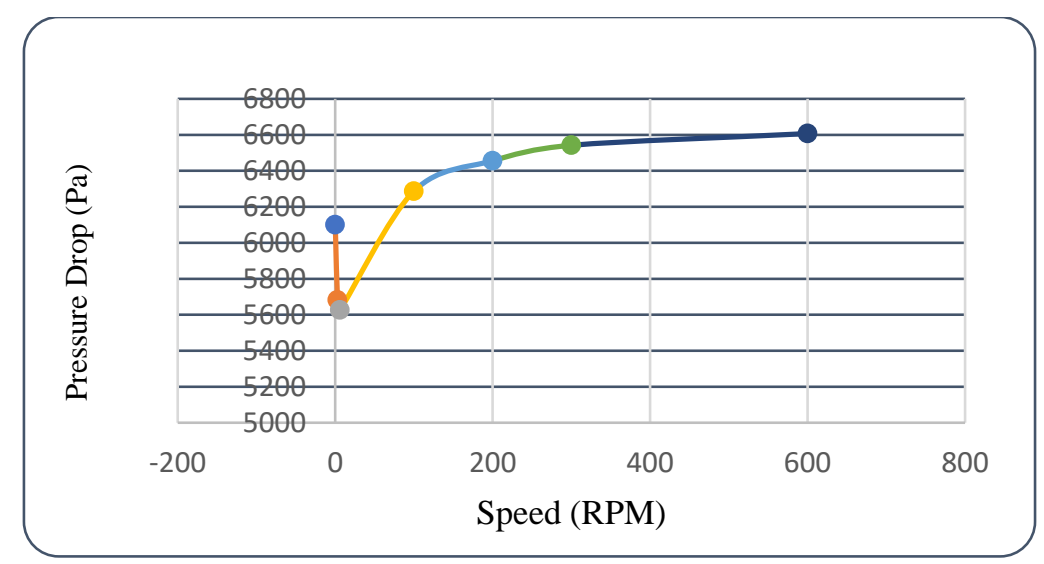

Fig. 8. Pressure drop with the speed of inner wall

It is clear that up to $100 \mathrm{rpm}$, pressure drop decreased, after that, it exhibited a visible increase. At slow rotational speed, the inner cylinder shears the fluid surrounding it and reduces the viscosity of the fluid. This is equivalent to adding energy to the fluid. Thus the pressure drop decreases up to a limit. But after a limit; higher speed only causes high energy dissipation due to the high fluid strain rate. Thus, the rotational speed of $100 \mathrm{rpm}$ can be considered to be an optimal one. The variation of average wall shear stress and skin friction coefficient are shown in Figs.9 and 10 respectively. Both the parameters decrease up to $6 \mathrm{rpm}$ after that it increases. This is as expected from the discussion of the nature of Fig. 8.

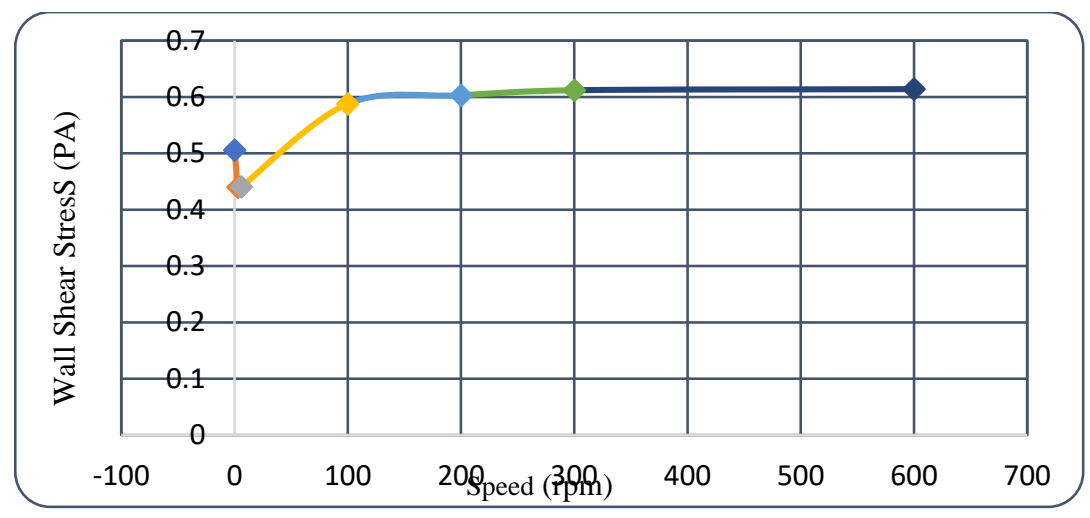

Fig. 9. Variation of wall shear stress with rotational speed

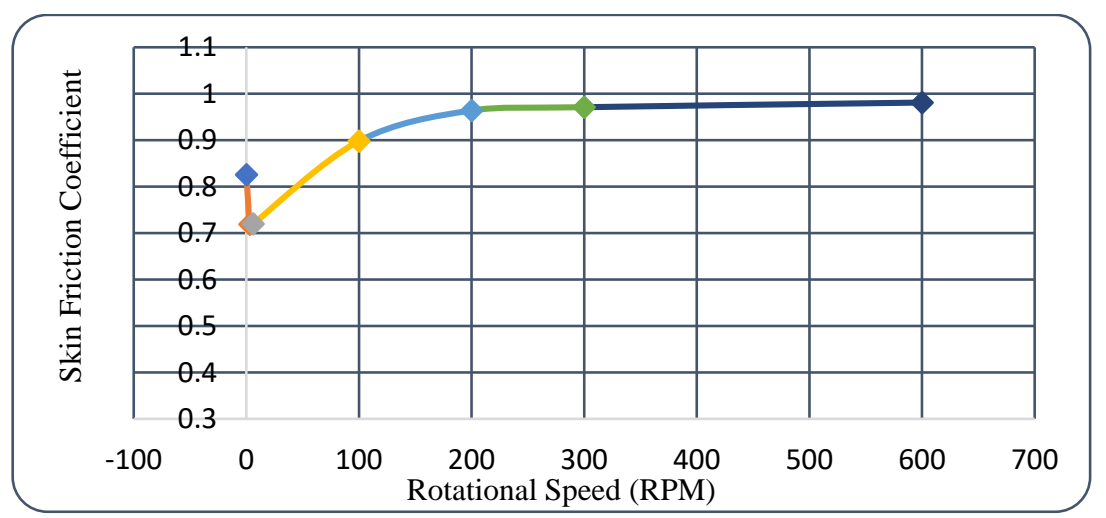

Fig. 10. Variation of skin friction coefficient with speed 


\subsection{Results of the experimental study}

Present work uses the experimental study to compare with the results of simulation in terms of pressure loss and carrying cuttings. The results of calibration revealed that water needs six minutes to carry all the plastic cuttings. Since the plastic cuttings have a low density less than water density. For the next experiment using water to carry the gravels, however; the experiment failed because of gravel density is higher than water density, which could not able to carry and transfer to the separator part as shown in Figure. 11. In the same time, there is not any pressure drop occurred. The reason was frictionless between plastic cuttings and the wall of the outer cylinder.

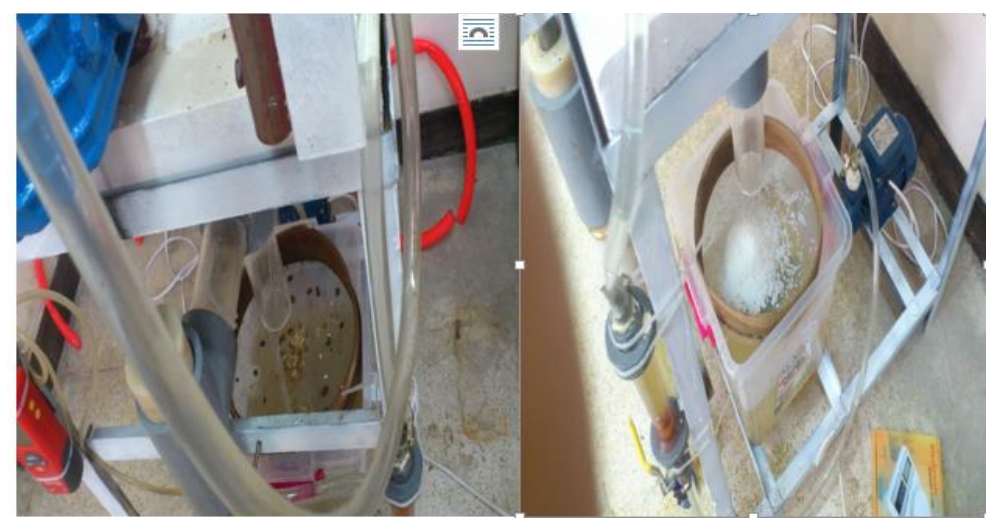

Fig. 11. Calibration experiment

Pressure losses during the circulation of water-based fluid are very close to that getting from the simulation study. Specifically, the supplied hydrostatic pressure is 1.42-psi (9790.56 Pa) using equation no.8, and the measured pressure through annulus was 6.29 $\mathrm{Pa}$. Therefore the pressure loss is $9784.27 \mathrm{~Pa}$. Lab photos confirmed the validity of simulation results as clear in Fig. 12.

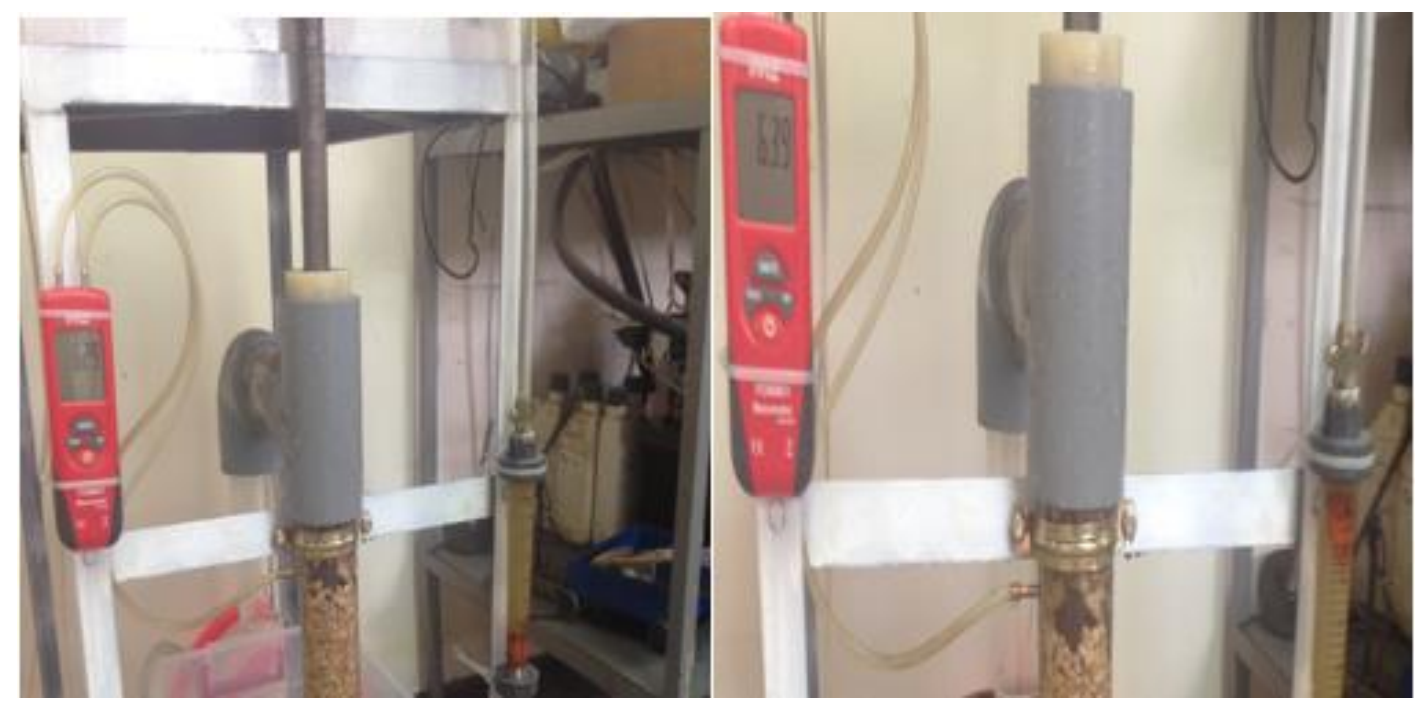

Fig. 12. Lab photos of manometer readings

Table 1 illustrates the selected data of experimental measurements. From table 1, the pressure drop through annular space with $100 \mathrm{rpm}$ of inner cylinder rotational speed is 9783.67 comparing to the simulation results that reveal that pressure drop with zero eccentricity is $7900 \mathrm{pa}$. 
Table 1 explains the experimental results.

\begin{tabular}{|c|c|c|c|c|c|}
\hline $\begin{array}{c}\text { Mass of } \\
\text { gravels(g) }\end{array}$ & $\mathrm{P}_{\text {in }}(\mathrm{pa})$ & Manometer(pa) & $\Delta \mathrm{P}(\mathrm{pa})$ & $\begin{array}{c}\text { mass } \\
\text { carried }(\mathrm{g})\end{array}$ & time(min) \\
\hline 1600 & 9790.56 & 6.39 & 9784.27 & 50 & 5 \\
\hline 1600 & 9790.56 & 6.69 & 9784.17 & 112 & 23 \\
\hline 1600 & 9790.56 & 6.77 & 9783.89 & 210 & 24 \\
\hline 1600 & 9790.56 & 6.80 & 9783.79 & 280 & 26 \\
\hline 1600 & 9790.56 & 6.89 & 9783.76 & 390 & 26 \\
\hline 1600 & 9790.56 & 6.94 & 9783.62 & 410 & 29 \\
\hline
\end{tabular}

As a result, the difference between them is $19 \%$. This error percentage can be considered as an acceptable range referring to the design accuracy of the apparatus and the scaling down from the real device to the prototype size. It can be seen from Table 1, water-based mud can carry the gravels of $74 \%$ using the following equation:

$$
\text { Carrying cabacity }=\frac{M_{1}-M_{2}}{M_{1}}
$$

$M_{1}$ : Gravels amount before drilling $(\mathrm{g})$

$M_{2}$ : Gravels amount out to separator part (g)

For this carrying ability, there is an agreement with the simulation model that related to the volume fraction of cuttings as cleared in Figure 10.

\section{Conclusions}

The simulation model of Bingham plastic fluid inside vertical concentric annuli with and without rotation is considered. Temperature distribution and pressure drop profile along drill pipe depth are studied. Different eccentricities with different rotational speeds, 0.2 of eccentricity lead to increase the pressure drop inside annuli. A prototype of a drilling device is manufactured to compare with the simulation results. Drill pipe rotational speeds affect Bingham plastic fluid performance significantly, in terms of viscosity, pressure drop, shear stress, and Fanning friction coefficient. Wellbore temperature has an opposite effect on the Bingham plastic model. Drill pipe rotational speed of $100 \mathrm{rpm}$ is considered as an optimum speed. The eccentricity of 0.2 leads to increase the pressure drop inside annuli. There is a good agreement between pressure losses during the circulation of water-based fluid and that getting from the simulation study.

\section{Acknowledgment}

The authors would like to thank Mustansiriyah University for their financial support 


\section{Nomenclatures}

$D_{\text {i: }}$ outside drill pipe diameter, $101.6 \mathrm{~mm}$

$\mathrm{D}_{\mathrm{c}}$ : inside casing pipe diameter, $203 \mathrm{~mm}$

$f$ :Fanning friction factor, $\left(\delta / \rho U^{2}\right)(\partial p / \partial z)$

$\mathrm{g}$ : gravity, $\mathrm{m} / \mathrm{s}^{2}$

$\mathrm{k}$ : thermal conductivity, $\mathrm{J} / \mathrm{kg} . \mathrm{K}$

p: pressure, $\mathrm{Pa}$.

$\bar{p}$ : non-dimensional pressure, $2 p \delta / \mu \theta D_{i}$

r: radial distance, $\mathrm{mm}$

$r^{-}$: non-dimensional value of $r / \delta$

$R e_{r}:$ rotational Reynolds number, $\rho \theta D_{i}^{2} / 4 \mu$

Re: bulk Reynolds number $2 \rho \cup \delta / \mu$

$u$ : axial velocity component, $\mathrm{m} / \mathrm{s}$

$u$ : non-dimensional value of $u, u / U$ $v$ : tangential velocity component $(\mathrm{m} / \mathrm{s})$

$v$ non-dimensional value of $v, 2 v / \theta D_{i}$

$w$ : radial velocity component, $(\mathrm{m} / \mathrm{s})$

$w$ : radial velocity component, $(\mathrm{m} / \mathrm{s})$

$\mathrm{Z}$ : axial distance, $\mathrm{m}$

$\delta$ : mean annular gap width, $D_{0}-D_{i} / 2, \mathrm{~mm}$

$\mu$ : fluid viscosity, Pa.s

$\rho$ : fluid density, $\mathrm{kg} / \mathrm{m}^{3}$

$\emptyset$ : azimuthal location with respect to inner cylinder

$\theta:$ angular velocity of inner cylinder $(\mathrm{rad} / \mathrm{s})$

\section{References:}

[1] S.R. Shadizadeh, M. Zoveidavianpoor, An experimental modeling of cuttings transport for an Iranian directional and horizontal well drilling, Pet. Sci. Technol. 30 (2012) 786-799..

[2] N.H. Ebrahim, M. Awang, ACCEPTED MANUSCRIPT, Int. J. Comput. Methods Eng. Sci. Mech. (2016) 1-36

[3] B. Amanna, M.R. Khorsand Movaghar, Cuttings transport behavior in directional drilling using computational fluid dynamics (CFD), J. Nat. Gas Sci. Eng. 34 (2016) 670-679.

[4] N.V. Boyou, I. Ismail, W.R. Wan Sulaiman, A. Sharifi Haddad, N. Husein, H.T. Hui, K. Nadaraja, Experimental investigation of hole cleaning in directional drilling by using nano-enhanced water-based drilling fluids, J. Pet. Sci. Eng. 176 (2019) 220-231.

[5] B. Pang, S. Wang, C. Lu, W. Cai, X. Jiang, H. Lu, Investigation of cuttings transport in directional and horizontal drilling wellbores injected with pulsed drilling fluid using CFD approach, Tunn. Undergr. Sp. Technol. 90 (2019) 183-193.

[6] E.I. Epelle, D.I. Gerogiorgis, Drill cuttings transport and deposition in complex annular geometries of deviated oil and gas wells: A multiphase flow analysis of positional variability, Chem. Eng. Res. Des. 151 (2019) 214-230.

[7] B. Werner, V. Myrseth, A. Saasen, Viscoelastic properties of drilling fluids and their influence on cuttings transport, J. Pet. Sci. Eng. 156 (2017) 845-851.

[8] S. Gulraiz, K.E. Gray, Investigating the effects of plug viscosity on annular pressure drop and 
cuttings transport in a concentric annulus, J. Nat. Gas Sci. Eng. (2020) 103210.

[9] A. V. Minakov, V.A. Zhigarev, E.I. Mikhienkova, A.L. Neverov, F.A. Buryukin, D. V. Guzei, The effect of nanoparticles additives in the drilling fluid on pressure loss and cutting transport efficiency in the vertical boreholes, J. Pet. Sci. Eng. 171 (2018) 1149-1158.

[10] J.O. Oseh, M.N.A. Mohd Norddin, I. Ismail, A.O. Gbadamosi, A. Agi, A.R. Ismail, Experimental investigation of cuttings transportation in deviated and horizontal wellbores using polypropylene-nanosilica composite drilling mud, J. Pet. Sci. Eng. 189 (2020) 106958.

[11] M.P. Escudier, I.W. Gouldson, P.J. Oliveira, F.T. Pinho, E ffects of inner cylinder rotation on laminar $^{-}$ow of a Newtonian ${ }^{-}$uid through an eccentric annulus, Int. J. Heat Fluid Flow. 21 (2000) 92-103.

[12] T.L. Skjold, Drillpipe Rotation Effects on Pressure Losses, (2012).

[13] V.C. Kelessidis, P. Dalamarinis, R. Maglione, Journal of Petroleum Science and Engineering Experimental study and predictions of pressure losses of fl uids modeled as Herschel - Bulkley in concentric and eccentric annuli in laminar, transitional and turbulent fl ows, J. Pet. Sci. Eng. 77 (2011) $305-312$.

[14] T. Cite, T. Article, E ngineering, 5 (2013) 10-17.

[15] H. Wang, Q. Bi, G. Wu, Z. Yang, Experimental investigation on pressure drop of supercritical water in an annular channel, J. Supercrit. Fluids. (2017).

[16] H. Yang, J. Li, G. Liu, J. Wang, K. Luo, B. Wang, Development of transient heat transfer model for controlled gradient drilling, Appl. Therm. Eng. 148 (2019) 331-339.

[17] J. Cai, Y. Duan, Study on temperature distribution along wellbore of fracturing horizontal wells in oil reservoir, Petroleum. 1 (2015) 358-365.

[18] M.R. Mahdiani, E. Khamehchi, A novel model for predicting the temperature pro fi le in gas lift wells, Petroleum. 2 (2016) 408-414.

[19] M.A.M. Ali, W.M. El-Maghlany, Y.A. Eldrainy, A. Attia, Heat transfer enhancement of double pipe heat exchanger using rotating of variable eccentricity inner pipe, Alexandria Eng. J. 57 (2018) 3709-3725.

[20] M. Tang, T. Zhang, S. He, L. Kong, H. Li, Q. Li, Journal of Natural Gas Science and Engineering Modeling of laminar fl ow in an eccentric elliptical annulus for YPL fl uid, 64 (2019) 118-132. 